\title{
Transumbilical Totally Laparoscopic Single-Port Nissen Fundoplication: A New Method of Liver Retraction: The Istanbul Technique
}

\author{
Ismail Hamzaoglu • Tayfun Karahasanoglu • \\ Erman Aytac • Adem Karatas • Bilgi Baca
}

Received: 13 December 2009 / Accepted: 18 February 2010/Published online: 20 March 2010

(C) 2010 The Author(s). This article is published with open access at Springerlink.com

\begin{abstract}
Introduction Mustafa Kemal Atatürk, founder of the Turkish Republic, had guarded many German scientists of a Jewish descent before the Second World War. Dr. Rudolf Nissen was one of the outstanding surgeons who had served in the Turkish university hospitals. He had created an antireflux procedure which is named after his own name while he was working in our clinic, the Cerrahpaşa Hospital. From a laparoscopic approach, the Nissen fundoplication was the gold standard intervention for the surgical treatment of gastroesophageal reflux disease (GERD). Currently, video laparoscopic surgery is evolving quickly with the guidance of new technology. Single-port (SP) laparoscopic transumbilical surgery is one of the newest branches of advanced laparoscopy.

Discussion Simple or complex manipulations may be performed with SP laparoscopic transumbilical surgery. The advantages, which are gained from conventional laparoscopy, can be invigorated by an SP laparoscopic approach. The retraction technique of the liver and the optical system were the most important factors, which made the Nissen fundoplication possible via single port. Here, we report that totally laparoscopic transumbilical SP Nissen fundoplication procedure was performed in three patients for sliding hiatal hernia with GERD.

Conclusion Totally laparoscopic transumbilical SP Nissen fundoplication is a safe and feasible technique for the surgical treatment of GERD.
\end{abstract}

Keywords Nissen fundoplication · Single port .

Laparoscopy $\cdot$ Transumbilical $\cdot$ Gastroesophageal reflux

\section{Introduction}

Mustafa Kemal Atatürk, who is the founder of the Turkish Republic, had invited many German scientists of a Jewish

Electronic supplementary material The online version of this article (doi:10.1007/s11605-010-1183-1) contains supplementary material, which is available to authorized users.

I. Hamzaoglu • T. Karahasanoglu • E. Aytac • A. Karatas • B. Baca Department of Surgery, Cerrahpasa Medical School, Istanbul University,

Istanbul, Turkey

I. Hamzaoglu $(\bowtie)$

Valikonagi Cad. No:173, Kat:14, D:4, 34363, Nisantasi, Istanbul, Turkey

e-mail: ihhamzaoglu@yahoo.com descent to Turkey before the Second World War. Dr. Rudolf Nissen was one of those precious medical doctors who had accepted Atatürk's invitation and came to live and work in Turkey. ${ }^{1-3}$

$\mathrm{He}$ was enthusiastically welcomed in Turkey and appointed as the Chief of the First Surgery Clinic in Istanbul University, the Cerrahpaşa Hospital, in 1933.

Nissen performed his first Nissen fundoplication operation in Istanbul on a 28 -year-old man with a bleeding distal esophageal ulcer in 1936. He resected the distal esophagus and proximal stomach and reconstructed it in a fashion that embedded the esophageal stump into the wall of the stomach. He had noticed that the patient had not complained from reflux symptoms. He had described his technique in 1936 in Turkish and in 1937 in German. ${ }^{4} \mathrm{He}$ developed this technique and he described this antireflux procedure called gastroplication in $1956 .{ }^{5}$ Dr. Nissen had worked on the antireflux procedure and published an improved version of the technique. He has given this 
technique its currently known name, fundoplication. ${ }^{6}$ His student Rosetti and later Deemester and Donahue improved this $360^{\circ}$ fundoplication. ${ }^{7-9}$ Different types of antireflux procedures have been published afterwards. However, laparoscopic approach has made the Nissen fundoplication the gold standard intervention for the surgical treatment of gastroesophageal reflux disease (GERD) since its application in the early 1990 s with the development of minimally invasive techniques. ${ }^{10,11}$

Single-port (SP) laparoscopic surgery is one of the newest branches of advanced laparoscopy. Simple or complex surgical procedures such as appendectomy, sleeve gastrectomy, or colorectal resections may be currently performed with SP laparoscopic surgery. ${ }^{12-15}$

Herein, we present a transumbilical totally laparoscopic SP Nissen fundoplication procedure that was performed in three patients for sliding hiatus hernia and GERD symptoms. A cholecystectomy procedure had been performed in one of the patients because of symptomatic cholelithiasis at the same time.

\section{Patient and Methods}

All patients were complaining about reflux symptoms. During the evaluation process, sliding type hiatus hernia causing GERD was diagnosed in all patients. One of the patients had also symptomatic cholelithiasis with multiple gallstones confirmed by liver ultrasonography. The blood biochemistries of the patients were in the normal limits.

The patients fully consented to the operation and a detailed information consent form was also signed by each patient. They were aware of being our initial cases for this specific procedure. We explained to the patients that, as an initial procedure, this technique would bring them no benefit, but it would reduce the wound size relatively. Furthermore, they were fully aware that we would need to use an additional port or would convert the operation to open surgery in the event of intraoperative difficulty or complication.

Surgical Procedure of Transumbilical Totally Laparoscopic SP Nissen Fundoplication

The patients were placed in supine position with the sacrum at the edge of the table and the two legs abducted on the boards were fixed to the operating table. The surgeon stood between the patient's legs and the first assistant stood on the patient's right side. Under general anesthesia, the SILS Port $^{\mathrm{TM}}$ (SILS ${ }^{\mathrm{TM}}$ Port $12 \mathrm{~mm}$, Covidien AG, Norwalk, Connecticut, USA) was introduced (open technique) into the abdomen through the umbilicus. All surgical procedures were performed intracorporeally. A 5-mm flexible laparo- scope with integrated camera $\left(\right.$ Olympus $^{\circledR}$, Orangeburg, New York) using the HD-TV EXERA 2 System (LTF$\mathrm{VH}$, Olympus) was used to allow two 5-mm instruments to work in a synchronized way. Under the guide of the laparoscope, a routine exploration was performed.

The Istanbul Technique Retraction of the liver without inserting an additional trocar is a problem for making SP transumbilical interventions for upper gastrointestinal tract surgery. Various liver retraction techniques have been described before. ${ }^{16}$ The main principle of the Istanbul Technique is an atraumatic suspension of the liver with a mechanism like a hammock. A Penrose drain $8 \mathrm{~cm}$ long and $1 \mathrm{~cm}$ wide was prepared for this retraction method. Two silk sutures in $10 \mathrm{~cm}$ lengths were tied to the two different ends of the Penrose drain. Then, it was inserted through a $10-\mathrm{mm}$ trocar of the SILS Port. The left triangular ligament was opened by Ultracision (Harmonic Ace, Ethicon Endosurgery ${ }^{\circledR}$, Cincinati, OH), leaving approximately $1 \mathrm{~cm}$ intact to prevent the slipping of the retraction mechanism. The Penrose drain was passed through the foramen in the left triangular ligament with the guidance of the silk laces and placed below the lateral segment of the liver. The silk laces tied on the edges of a Penrose drain were taken out of the abdomen with a device that was created from an 18-gauge Spinocan. This percutaneous suture-passing technique had been described previously by Dunning and Kohli. ${ }^{17}$ These silk laces were taken out of an appropriate place to retract the left lateral segment of the liver and fixed above the skin with the help of a clamp. We called this maneuver the Istanbul Technique (Fig. 1).

An articulating endograsper (Roticulator Endo Grasp ${ }^{\mathrm{TM}}$ with Lock, Covidien AG, Norwalk, Connecticut, USA) was used for retracting the stomach during the dissection.

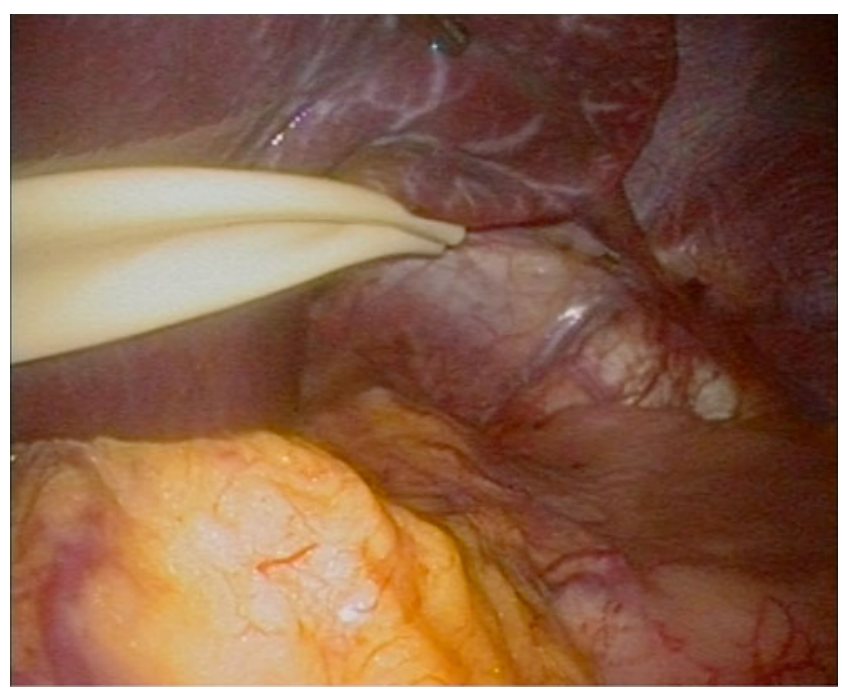

Fig. 1 Laparoscopic view of the retraction of the left lateral lobe of the liver with the Penrose drain (the Istanbul Technique). 
Portions of the right and the left crus of the diaphragm and the distal part of the esophagus were dissected. The whole dissection was performed with Harmonic Ace. Dissection of the fundus was started where the short gastric vessels appeared. Cruroraphy was performed with two silk stitches before creating the fundoplication. A 10-mm endoscopic suturing device (SILSTM STITCH, Covidien ${ }^{\circledR}$ AG, Norwalk, Connecticut, USA) was used for stitching. The floppy Nissen fundoplication was created without difficulty after finishing the dissection. Because we prefer a floppy fundoplication, we do not use any size of orogastric bougie for calibration. The fundoplication was performed with two silk stitches. One of the two stitches passing from the muscular layer of the esophagus was performed using an endoscopic needle holder. Finally, the fundoplication was fixed to the right crus of the diaphragm (Fig. 2). The Penrose drain was retrieved with the SILS Port after releasing the silk laces and the SILS Port site was closed. Entire operation could be watched in electronic supplementary material section.

Surgical Procedure of Transumbilical Totally Laparoscopic SP Cholecystectomy

The gall bladder was hung from the corpus to the abdominal wall with a silk suture after inserting the SILS Port. An articulating endograsper was used to create triangulation during the dissection of the cystic duct and the cystic artery. All the dissection was performed with Harmonic Ace. The cystic duct and the cystic artery were ligated by use of $5-\mathrm{mm}$ polymer endoclips (Hem-O-Lock, Weck Closure Systems, North Carolina, USA) and transected. The gall bladder was separated from the liver. The gall bladder was taken out of the abdominal cavity from the umbilicus.

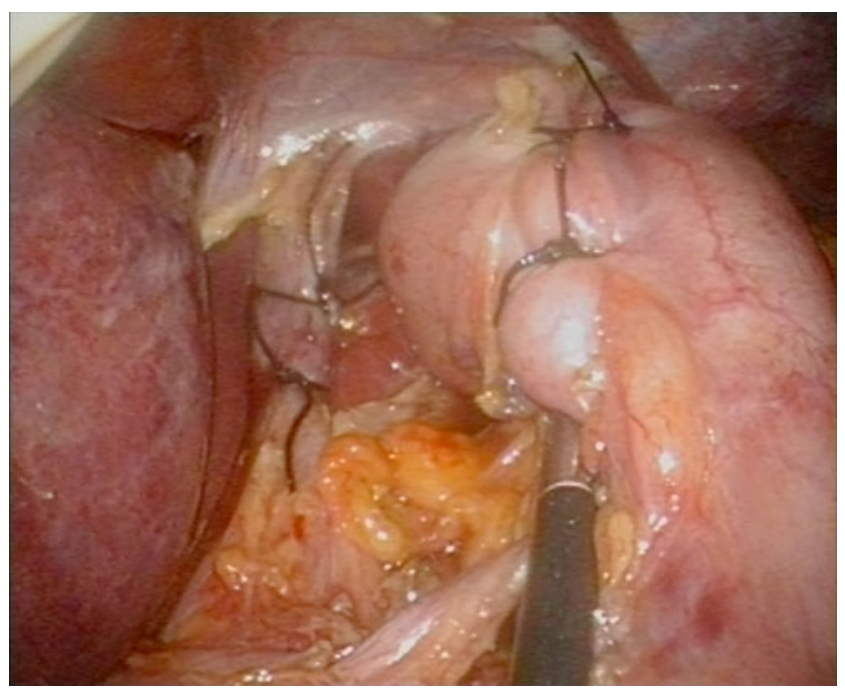

Fig. 2 Laparoscopic view of performed transumbilical SP Nissen fundoplication.
Table 1 Patients' Characteristics

\begin{tabular}{llll}
\hline & Case 1 & Case 2 & Case 3 \\
\hline Age & 23 & 40 & 58 \\
Gender & Female & Male & Female \\
Operating time $(\mathrm{min})$ & 180 & 180 & 210 \\
Body mass index $\left(\mathrm{kg} / \mathrm{m}^{2}\right)$ & 23 & 24 & 32 \\
Blood loss $(\mathrm{ml})$ & 20 & 50 & 20 \\
Post operative hospital stay (days) & 2 & 2 & 2 \\
\hline
\end{tabular}

\section{Results}

There were three patients who underwent transumbilical totally laparoscopic SP Nissen fundoplication. One of these also had a SP laparoscopic cholecystectomy. Patients' characteristics were shown in Table 1. Mean operative time was $190 \mathrm{~min}$ (180-210 min). Operative time was longer in the patient who underwent cholecystectomy. Mean blood loss was $30 \mathrm{ml}(20-50 \mathrm{ml})$. No drain was used. The patients started a soft oral diet $12 \mathrm{~h}$ after the surgery and were discharged uneventfully on postoperative day2. Umbilical scar was almost invisible 1 week after the operation (Fig. 3).

\section{Discussion}

Prior to GERD surgery, the patients can be gathered in three separate groups such as nonerosive reflux disease, erosive esophagitis, or Barrett's esophagus. In nonerosive GERD patients, pH study should be performed. Manometric studies are very helpful during the evaluation of patients,

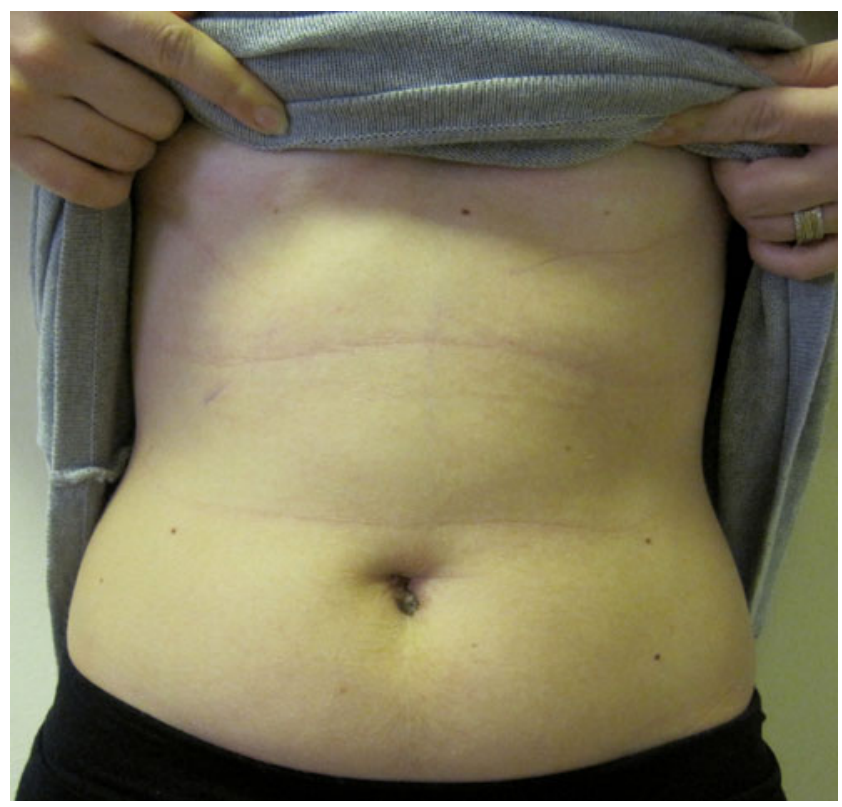

Fig. 3 Photograph of the patient 1 week after the operation. 
especially those who show atypical symptoms and patients suspected of having esophageal motor disorders. In each of the three patients who showed typical GERD symptoms, the diagnosis was made by esophagogastroduodenoscopy. All of the patients were diagnosed with grade I-II erosive esophagitis and small hiatal hernia (type I). The patients' symptoms showed a good response to medical treatment. However, the symptoms started showing again when medical therapy was discontinued. In patients with dysphagia, upper gastrointestinal imaging can be performed before anything else. It is recommended that a gastric emptying study should be performed in selected patients.

Video laparoscopic surgery is evolving quickly with the guidance of new technology. SP transumbilical laparoscopy is the threshold technique during the adaptation period of the abdominal surgical interventions to the natural orifice transluminal endoscopic surgery. Umbilicus is a natural scar tissue and is an access for performing the SP transumbilical surgery, which preserves the body image perfectly with a lesser scar.

The superiority of the laparoscopic Nissen fundoplication has been proved against the open techniques for the surgical treatment of GERD. ${ }^{18}$ The advantages, which are gained from the conventional laparoscopy, can be invigorated by the SP laparoscopic approach.

In this initial experience, we reported three patients who underwent transumbilical laparoscopic SP Nissen fundoplication and found that this novel technique was safe and feasible comparing with the other minimally invasive techniques. The patient satisfaction was superior and they were very happy to preserve their body image with this almost scarless surgery. To our knowledge, this is the first peer-reviewed publication describing transumbilical laparoscopic SP Nissen fundoplication.

SP laparoscopic surgery requires more advanced laparoscopic skills. There is only one access and the use of the instruments may complicate to continue the operation. For this kind of difficult surgical interventions, surgeons have developed some techniques which make operation safe and easy. In this study, the authors improved a new retraction method for liver retraction. The retraction technique of the liver is the most important factor which makes the Nissen fundoplication, obesity surgery, and gastric surgery applicable via a single port. We also think this technique can be applied during multiport laparoscopy and will prevent bleeding from the liver due to retraction. The Istanbul Technique can provide an atraumatic liver retraction and can fully expose the esophagogastric region. SP laparoscopic Nissen fundoplication can be performed safely with the help of this retraction technique.

The GERD patients who have no or small hiatal hernia could be good candidates for single-port antireflux surgery (SPARS). When the surgeons complete the learning curve period for SPARS, they could perform more complicated procedures with the help of new techniques and technology.

This procedure can be done using transumbilical or epigastric incision. The distance between the xiphoid edge and the umbilicus could be an important factor for performing the transumbilical laparoscopic SP Nissen fundoplication. In our older patient, this distance was very long and this factor caused difficulties during the surgery. It becomes harder to reach the area of the surgery, to make manipulations, and to visualize. In these patients who have longer xiphoid-umbilicus distances, an epigastric incision can be used. However, another incision far away from umbilicus for laparoscopic SP access will not be as scarless as transumbilical access.

From a cosmetic perspective, it leaves an almost invisible scar. It is almost impossible to see the scar a few months after the surgery. It preserves the patients' body image. This is especially important for younger patients such as our 23-year-old patient. The patients feel less traumatized and feel as if they are not ill because they do not have any scars on their abdomen. Because of this, they feel better about the procedure from the first moment on. It is not a hundred percent certain, but it is predicted that there is less pain as well. It is expected there will be less bleeding from the postoperative trocar sites.

There are two limitations of the SP laparoscopic Nissen fundoplication. One of them is the incisional hernia risk and the other one is the longer operation time. There is a concern about the incisional hernia risk of this larger incision of the fascia comparing with the conventional laparoscopic surgery. However, there has been no published data regarding increased incisional hernia risk in transumbilical SP laparoscopic surgery. Currently, the probability of this complication can be only an issue for further prospective randomized controlled trials. The other limitation is the longer operation time. Current surgical devices of the SP surgery and the experience of the laparoscopic surgeons are not sufficient to perform these procedures as fast as the conventional minimally invasive procedures. Improved instruments like articulating energy devices will make these procedures easier to perform. More complicated procedures such as bariatric operations will be performed with the help of these developing devices and with the help of the newly discovered techniques like the Istanbul Technique.

Totally laparoscopic transumbilical SP Nissen fundoplication is a safe and feasible technique for the surgical treatment of GERD. Prospective randomized trials are required to assess the long-term results comparing transumbilical laparoscopic SP Nissen fundoplication with laparoscopic Nissen fundoplication.

Acknowledgements The authors gratefully thank to Dr. Arif Sami Kahya, Sibel Akbay, and Mega Ozel Saglik Hizmetleri A.S. (on behalf of Turkey Distributor of Olympus Endoscopic Systems). 
Open Access This article is distributed under the terms of the Creative Commons Attribution Noncommercial License which permits any noncommercial use, distribution, and reproduction in any medium, provided the original author(s) and source are credited.

\section{References}

1. Goksoy E, Sertel I, Gokdogan C. Ein deutscher Professor für Chirurgie in Istanbul (1933-1939): Ord. Prof. Dr. Rudolf Nissen. Langenbeck Archiv für Chirurgie Heidelberg: Springer, 1996:1262-1263.

2. Dogan H, Topcu I. Rudolf Nissen (1896-1981): his contributions to surgery and his role in Turkey. Isr Med Assoc J 2009;11:255-258.

3. Batirel HF, Yuksel M. Rudolf Nissen's years in Bosphorus and the pioneers of thoracic surgery in Turkey. Ann Thorac Surg 2000;69:651-654.

4. Nissen VR. Die transpleurale resektion der kardia. Dtsch Z Chir 1937;249:311-316.

5. Nissen R. [A simple operation for control of reflux esophagitis.]. Schweiz Med Wochenschr 1956;86:590-592.

6. Nissen R. Gastropexy and "fundoplication" in surgical treatment of hiatal hernia. Am J Dig Dis 1961;6:954-961.

7. Rosetti ME, Liebermann-Meffert D, Nissen-Rossetti fundoplication (open procedure). In Baker RJ, Fischer JE, eds. Mastery of Surgery. Philadelphia: Lipincott, Williams and Wilkins, 2001, 764-767.
8. Demeester TR, Johnson LF, Kent AH. Evaluation of current operations for the prevention of gastroesophageal reflux. Ann Surg 1974;180:511-525.

9. Donahue PE, Larson GM, Stewardson RH, Bombeck CT. Floppy Nissen fundoplication. Rev Surg 1977;34:223-224.

10. Liebermann-Meffert D. Rudolf Nissen (1896-1981)—perspective. J Gastrointest Surg 2009; in press.

11. Geagea T. Laparoscopic Nissen's fundoplication: preliminary report on ten cases. Surg Endosc 1991;5:170-173.

12. Roberts KE. True single-port appendectomy: first experience with the "puppeteer technique". Surg Endosc 2009;23:1825-1830.

13. Geisler DP, Condon ET, Remzi FH. Single incision laparoscopic total proctocolectomy with ileopouch anal anastomosis. Colorectal Dis 2009; in press.

14. Saber AA, El-Ghazaly TH, Elian A. Single-incision transumbilical laparoscopic sleeve gastrectomy. J Laparoendosc Adv Surg Tech A 2009;19:755-758 (discussion 9).

15. Hamzaoglu I, Karahasanoglu T, Baca B, Karatas A, Aytac E, Kahya AS. Single port laparoscopic sphincter saving mesorectal excision for rectal cancer: report of the first four human cases. Arch Surg 2010; in press.

16. Sakaguchi Y, Ikeda O, Toh Y, Aoki Y, Harimoto N, Taomoto J, Masuda T, Ohga T, Adachi E, Okamura T. New technique for the retraction of the liver in laparoscopic gastrectomy. Surg Endosc 2008;22:2532-2534.

17. Dunning K, Kohli H. Transumbilical laparoscopic cholecystectomy: a novel technique. Arch Surg 2009;144:957-960.

18. Salminen PT, Hiekkanen HI, Rantala AP, Ovaska JT. Comparison of long-term outcome of laparoscopic and conventional nissen fundoplication: a prospective randomized study with an 11-year follow-up. Ann Surg 2007;246:201-206. 